Contemporary feminist thinking

Thinking again politics in crisis time

\title{
Pensamiento feminista contemporáneo (Re)pensar la politica en tiempos de crisis
}

\author{
Silvia L. Gil
}

Universidad Iberoamericana de México silvia@sindominio.net

DOI: http://dx.doi.org/10.15366/bp2018.18.011

Bajo Palabra. II Época. No18. Pgs: 237-254

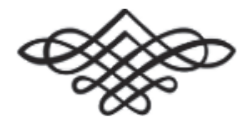


Recibido: 30/11/2016

Aprobado: 29/07/2018

\section{Resumen}

Algunas de las categorías vinculadas a la interpretación hegemónica del Ser en Occidente han sido cuestionadas a lo largo de la segunda mitad del Siglo XX por diferentes corrientes como la filosofía feminista. Conceptos como sujeto, comunidad o política han entrado en crisis. ¿Qué cabe decir de ellos en la actualidad? Las aportaciones de los feminismos al respecto son cruciales, principalmente por su atención al problema de la diferencia y de las identidades múltiples. En este artículo, se analiza el modo en el que estas aportaciones contribuyen a repensar la ontología y la política, con el objetivo de abordar un debate clave en el momento actual de «crisis» sistémica o civilizatoria: cómo construir una vida vivible para todas las personas, pero sin renunciar al mismo tiempo al reconocimiento de las diferencias.

Palabras clave: filosofia feminista, diferencia, inacabamiento, común, política.

\section{Abstract}

Fundamental categories of a specific interpretation of Being in Western philosophy has been brought into cuestion over the second half of twentieth century by different currents such as feminist philosophy. Key concepts in contemporary thinking as subject, community or politics have entered into crisis. What can we say about them today? The contributions of feminisms in this respect are crucial, mainly because of their attention to the problem of difference and the multiplity identities. In this article, we analyze the way in which these contributions contribute to rethinking ontology and politics, with the aim of tackling a key debate in the present moment of systemic or civilizing "crisis": how to build a life that is alive from the premise of equality, but without renouncing at the same time the recognition of differences.

Keywords: feminist philosophy, difference, incompleteness, common, policy. 


\section{Introducción}

UNA DE LAS CLAVES PARA COMPRENDER LA PERSISTENCIA de las formas de dominación sobre las mujeres es reconocer las complejas rearticulaciones del patriarcado en las que las asimetrías de género, lejos de desaparecer, se fortalecen. Los problemas como la violencia o la discriminación adquieren nuevas formas: el patriarcado no es un sistema de opresión monolítico y universal que, visto desde la perspectiva de las mujeres blancas del primero mundo, habría disminuido en sus efectos. Por el contrario, el patriarcado se reconfigura históricamente con otros sistemas como el racismo, el clasismo o el heterosexismo, diversificando las posiciones que habitan los sujetos. Esta complejidad reclama miradas analíticas y políticas no totalizantes, aterrizadas en los procesos históricos y atentas a las múltiples experiencias con el poder de las mujeres y de otros sujetos no normativos. En el contexto neoliberal, en el que las lógicas de dominio tratan de confundirse con la vida, cómo abordar este problema sin ceder a nuevas totalizaciones ni caer en relativismos se convierte en una pregunta crucial en nuestro tiempo.

Los debates que tienen lugar desde la década de los ochenta en el interior de la filosofía y la teoría feministas en torno al sujeto "Mujer» arrojan luz al respecto. En ellos, se evidencia la necesidad de romper con falsos universales herederos de cierto pensamiento moderno, cuestionar su neutralidad para que puedan aflorar diferencias, reducidas a meros accidentes o particularidades. Hay que señalar que esta necesidad no es solo teórica o abstracta, sino que se encarna como cuestión práctica, organizativa si se quiere, en las luchas feministas desde la década de los noventa. ${ }^{1}$ En la crisis del sujeto del feminismo, está en juego construir un movimiento de mujeres -y, con ello, abordar cierto proyecto común- que no reproduzca, como diría Gilles Deleuze, la misma identidad molar que pretende cuestionar. ${ }^{2}$ Por ello, las respuestas ensayadas a partir de este desafío se sitúan antes que nada en

\footnotetext{
${ }^{1}$ Para un estudio sobre dichas prácticas, véase, Gil, Silvia L., Nuevos Feminismos. Sentidos comunes en la dispersión, Madrid, Traficantes de Sueńos, 2011. doi:

2 Rosi Braidotti narra que preguntó a Deleuze cómo es posible que pretendiese al mismo tiempo que las mujeres devengan un movimiento molar que cambie la historia y un devenir minoritario que deshaga la categoría «Mujer». Deleuze respondió afirmando la paradoja: «Esto es un problema real y es absolutamente cierto; no se cómo resolverlo, dime tú cómo solucionarlo». Para Braidotti, en este punto los filósofos no pueden ir más lejos en relación al problema de la diferencia. «Ellos se detuvieron exactamente donde las feministas posmodernas comenzaron con la pregunta sobre esta contradicción, que es el modo como nosotras podemos defender y afirmar los derechos de las mujeres y redefinir el concepto de humanidad». Braidotti, Rosi, Feminismo, diferencia sexual y subjetividad nómade, Barcelona, Gedisa, 2004, pp. 228-229.
} 
la experiencia, en un terreno fronterizo entre teoría y práctica; terreno en el que la diferencia deja de ser un aspecto secundario para atravesar de manera inherente la misma noción de lo político.

En la actualidad, asistimos a una feminización de la politica, siempre que «femenino" se entienda como virtualidad y no como esencia, como prefiguración en curso, no como identidad. Esta feminización se produce en dos sentidos. El primero tiene que ver con el protagonismo adquirido por mujeres que defienden la vida en múltiples niveles frente a las políticas neoliberales; por ejemplo, ante los recortes y los desahucios en la periferia Sur de Europa o el despojo de las comunidades en Latinoamérica, África o Asia. El segundo se refiere a un modo de hacer específico que sostiene el desafío señalado de la diferencia, que puede observarse en las movilizaciones sociales de las multitudes como la Primavera Árabe, el \#YoSoy132 y \#Ayotzinapa en México, el 15M en España, Occupy Wall Street en USA o el movimiento Passe Livre en Brasil. Aquí, se replican algunos ingredientes singulares propios de las prácticas feministas: el reconocimiento desde una política de la diversidad, el cuerpo y las emociones, la preocupación por construir espacios heterogéneos e inclusivos de sociabilidad común, la fuga de posiciones polarizadas y prefijadas, la insistencia en el pacifismo y el énfasis en gestos micropolíticos que hacen mundo con otras gramáticas y coordenadas. Esta manera de desplegar la acción política, además de posibilitar protagonismos diversos, recuerda la importancia de cuidar la vida en su complejidad, en un momento en el que las dinámicas neoliberales se traducen en muerte en buena parte del planeta. En este sentido, puede decirse que estos movimientos intuyen que la feminización es necesaria para contrarrestar el neoliberalismo.

Las líneas que siguen parten de una idea doble. Por un lado, ver de qué modo los aportes feministas en los niveles ontológico y político contribuyen a comprender los procesos de politización en la actualidad, y a abordar el debate tan necesario como difícil sobre construir una vida vivible. Y no hacerlo, por otro lado, desde la necesidad de formar o educar en el feminismo. Esto significa que no se trata de desplegar una serie de respuestas programáticas o de recetas que deberían cumplirse. Se trata más bien de saber en qué sentido los feminismos contribuyen a crear nuevos imaginarios capaces de contagiar para una política otra.

\section{Deconstrucción de la metafísica}

UNO DE LOS ASPECTOS DE LA CRISIS que vivimos en la actualidad (considerada en su magnitud como crisis civilizatoria) es la quiebra de sentido de algunas de las ideas más profundas que sostienen la misma noción de «vida» en Occidente: Unidad, 
Sujeto, Universalidad, Presencia, Individuo... Estas nociones se erigen sobre un edificio metafísico que ha sido cuestionado por la teoría feminista y otras corrientes filosóficas contemporáneas (filosofía del deseo, filosofía de la diferencia, filosofía postestructuralista, ${ }^{3}$ etc.). Este edificio, que dio lugar a la ontología moderna, se ha construido según cuatro rasgos: unidad, totalidad, primado de la conciencia e identificación con el tiempo presente; aspectos que algunas autoras asocian al falogocentrismo ${ }^{4}$. Las críticas volcadas sobre aquél son prioritarias en la búsqueda de epistemologías y maneras de pensar diferentes, pues trastocan los fundamentos últimos de la realidad, con consecuencias importantes para la misma comprensión del mundo, pero también para la acción política.

\section{Unidad ¿imposible?}

Por lo pronto, la idea de unidad ha sido confrontada desde la triple experiencia de la diferencia que experimentan muchas mujeres, así como otros sujetos que habitan los márgenes de la norma sexo-género. Esta posición de subalternidad implica un punto de vista radicalmente materialista: se inscribe en el cuerpo a través de experiencias y memorias, en ocasiones dolorosas y violentas, que difícilmente pueden ser ignoradas. Por ello, se trata de un punto de vista parcial y encarnado; de una perspectiva que incluye algo de aquello que ha sido invisibilizado o borrado de los relatos hegemónicos. A este aspecto hay que sumarle la insistencia del feminismo en una identidad que siempre es múltiple y contradictoria, no unitaria. Simone de Beauvoir enfatizó en el Segundo Sexo que en cada mujer concreta habita La Mujer con mayúscula, ese constructo social que impone un modo homogéneo de ser, pensar y hacer. Dicha contradicción en el origen de la identidad femenina revela que aquello que nos define como mujeres -de modo ciertamente precario e inestable- es lo mismo que nos oprime, de tal forma que la liberación supone, paradójicamente, cierta destrucción: ir en contra de lo que me permite ser. De este modo, la posibilidad de emanciparse constituye una inquietante amenaza a la identidad: «necesito el feminismo para dejar de ser mujer», señalaba un cartel reciente. Como sostiene Teresa de Lauretis, existe un impulso que de manera simultánea rompe y subvierte, afirma y recompone la auto-representación femenina. ${ }^{5}$ Esta tensión

\footnotetext{
3 La misma noción de «deconstrucción» como se sabe es de Jacques Derrida.

4 Braidotti, Rosi (2002), Metamorfosis. Hacia una teoría materialista del devenir, Madrid, Akal, 2005; Irigaray, Luce (1974), Espéculo de la otra mujer, Madrid, Akal, 2007.

5 Lauretis, Teresa de, Diferencias. Etapas de un camino a través del feminismo, Madrid, Horas y horas, 2000, pp. 77-78.
} 
muestra que no hay identidad completa y sustantiva de la que partir: lo femenino es siempre un espacio en pugna. Sin embargo, dicha incompletud debe leerse también de manera positiva: en la medida en que no existe una esencia que pueda decirnos en qué consiste ser mujer, las posiciones de sujeto se expanden. Si trasladamos esta incomodidad en relación a las identidades al campo político, puede intuirse de qué modo una mirada compleja sobre el sujeto ha sido motivo suficiente para que las luchas feministas no se sometan a la unidad de un proyecto revolucionario. Se trata de asumir que el «sueño de un lenguaje común», como lo denomina Audre Lorde, solo puede edificarse desde los cimientos de la "casa de la diferencia». ${ }^{6} \mathrm{Y}$ edificar desde la casa de la diferencia supone asumir la contingencia: no es posible prever el devenir de la historia, los modos singulares de ser nunca son definitivos.

Por último, la idea de unidad se cuestiona a través del desafío que abre el problema del cuidado. ${ }^{7}$ El mandato histórico de sostener la vida cotidiana ha desafiado a las mujeres a convivir con la alteridad, con aquello Otro que no soy yo, pero que debo respetar y cuidar -sin que esto signifique que se trata de un proceso armónico, sin conflictos ni desgarramientos-. El cuidado - de las hijas e hijos, de personas mayores o enfermas- supone una relación íntima y contradictoria con lo diferente; se trata de responsabilizarse de una vida singular a la que nos sentimos vinculados y, al mismo tiempo, de garantizar su autonomía. Este movimiento entre interdependencia y autonomía es un aspecto clave en las sociedades contemporáneas globalizadas donde uno de los desafíos es reconstruir la posibilidad de una vida común. Pero, además, lo es en sociedades donde el Otro no puede interpretarse como simple exterioridad según el modelo colonial clásico, sino que habita en el interior de la misma cultura -aquél/aquélla que está entre nos(otros)-. Esta triple experiencia -subalternidad, multiplicidad y alteridad- invoca un pensamiento singular pegado a la piel, que desmantela la hegemonía de la razón como unidad abstracta. En tanto pensar ligado a la vida (en un sentido amplio), es un pensar de la relación de ese cuerpo con otros cuerpos -seduce, toca, afecta, contagia-; de un cuerpo que no puede entenderse sino en conexión con otras materialidades, nunca por sí mismo. Y como pensar de la diferencia -exceso, irrupción, desbordamiento- permite abandonar la victimización: no solo considerar lo que nos somete -aquellas condiciones materiales que preceden al sujeto-, sino lo que de diferente puede una vida.

\footnotetext{
${ }^{6}$ Lorde, Audre, Zami: A new spelling of my name; NY, The Crossing Press, 1982.

7 El trabajo de cuidado se refiere al conjunto de tareas destinadas a producir bienestar que son necesarias para que la vida se sostenga cotidianamente. Estas tareas son tanto materiales (las que tienen que ver con las llamadas tareas domésticas: limpiar, lavar, cocinar, comprar, etc.), como inmateriales (planificar, ordenar, comunicar, mediar, atender). Históricamente este trabajo ha sido asignado a las mujeres, produciendo una desigualdad estructural vinculada al origen del capitalismo (lo que se conoce como división sexual del trabajo).
} 


\section{Totalidades en ruptura}

Por su parte, la interpretación del ser como totalidad ha sido cuestionada desde diferentes perspectivas. Una de las más importantes en los debates políticos y filosóficos contemporáneos es la que defiende la posición femenina como no-todo, en consonancia con las lecciones de Jacques Lacan. Diferentes autoras insisten en la necesidad de tomar la diferencia sexual para descompletar al ser y desbordar la lógica del Uno; desborde que tiene lugar de modo similar a la mencionada experiencia subalterna, pero en un sentido ontológico, no solo social. ${ }^{8}$ Que no exista La Mujer quiere decir que nada sabemos acerca de su significado -éste no aparece inscrito en lo simbólico-; es decir, no es posible alcanzar una posición sexual definitiva. ${ }^{9}$ Esta noción introduce un resquebrajamiento en el interior del propio concepto y de su sentido, no porque no alcance a contener la realidad que lo desborda (porque haya múltiples subjetividades disidentes inclasificables), sino porque es imposible en sí mismo. Lo real de la diferencia sexual viene a desmantelar cualquier pretensión de totalidad desde su propia imposibilidad constitutiva. La segunda perspectiva crítica viene de la mano del pensamiento de las minorías, desde el que se ha interrogado a los proyectos de emancipación que han sido definidos a través de una única identidad -por ejemplo, la clase obrera ${ }^{10}$-. Desde la década de los ochenta, el surgimiento de problemáticas no contempladas en los marcos políticos clásicos - preocupación ecológica, reivindicaciones gays, étnicas y otras- ha obligado a redefinirlos. En esta dirección, el trabajo del feminismo descolonial ilumina modos de resistencia que, hilvanados en diversas partes del mundo, con otras gramáticas y estrategias, dan forma a propuestas epistemológicas novedosas (¿cuál es la potencia de un pensamiento del Sur?). Propuestas que recuperan el valor de narraciones locales frente a los relatos únicos, en este caso, el europeo, que ha sido impuesto como Historia universal. ${ }^{11}$

\footnotetext{
${ }^{8}$ La noción de «diferencia sexual» como matriz ontológica ha originado un interesante debate entre la teoría de género y el psicoanálisis lacaniano que puede verse en Butler, Judtih; Laclau, Ernesto y Zizek, Salvoj, Contingencia, hegemonía y universalidad. Diálogos contemporáneos de la izquierda, México, Fondo de Cultura Económica, 2003; y también en Zupančič, Alenka; Copjec, Joan y Cevasco, Rithée, Ser-para-el-sexo. Diálogo entre filosofía y psicoanálisis, Barcelona, Ediciones del Centro de Investigación Psicoanálisis y Sociedad, 2013.

9 En sentido estricto, según Lacan: «No hay la más mínima realidad prediscursiva, por la buena razón de que lo que se forma en colectividad, lo que he denominado los hombres, las mujeres y los niños, nada quiere decir como realidad prediscursiva. Los hombres, las mujeres y los niños no son más que significantes». Lacan, Jacques (1975), Aun. Seminario 20, Buenos Aires, Paidós, 2008, p. 44.

10 Como sostiene Carol Pateman, la clase es construida como una categoría patriarcal: «La clase trabajadora es la clase de los varones trabajadores, quienes, además, son ciudadanos plenos del Estado de bienestar». Pateman, Carol, «El estado de bienestar patriarcal», en Contextos, Ańo 2 No 5., Lima, Programa de Estudios de Género Pontificia Universidad Católica del Perú, 2000.

11 Parte de estas epistemologías del Sur es el esfuerzo por repensar la relación del ser humano con otros seres vivos y no vivos desde perspectivas comunitarias que implican un descentramiento del sujeto moderno. Para un acercamiento al pensamiento postcolonial véase, VV.AA. (2008), Estudios Postcoloniales. Ensayos fundamentales,
} 
En este sentido, la apuesta es incluir puntos de vista que complejicen dicho relato; puntos de vista que resultan imprescindibles en el mundo globalizado para construir procesos de emancipación incluyentes, que no reproduzcan viejas desigualdades o den lugar a nuevas. Por otra parte, mirar las subjetividades no hegemónicas, aquellas que escapan en algún sentido a la norma, ha permitido anudar alianzas que amplían el significado de lo femenino, llevando más lejos que nunca la pregunta qué significa ser mujer. Las imágenes convencionales son desplazadas por otras figuraciones -joven precaria, migrante transnacional, transgénero, treintañera sin familia, transexual, madre sola-. En este sentido, el pensamiento poscolonial y las políticas queer, ${ }^{12}$ en tanto herramientas que permiten cuestionar esencialismos y desplazar los imaginarios dominantes, reubican en el centro la voz de $\operatorname{los} \operatorname{Otros}^{13}$ y desestabilizan toda pretensión de unidad predefinida a priori.

\section{Subjetividad y tiempo ¿presente?}

Como anticipamos, otro de los pilares de la metafísica occidental, la identificación entre sujeto y conciencia, también va a ser interrogado. La presencia del inconsciente advierte de un sujeto que no controla su propio aparato psíquico. Desbordado, percibe que hay algo de la misma realidad que lo constituye que no puede conocer y que, sin embargo, lo determina en no pocos aspectos. A esta dislocación operada por el inconsciente, hay que sumar el papel que tienen otras dimensiones como la memoria y la imaginación, el deseo y el afecto. Si también conforman aquello que somos, ¿es posible concebir el mismo acto de pensar ignorando su importancia? Para Rosi Braidotti, solo puede hacerse forzando una división primaria entre mente y cuerpo, división que es en sí efecto del falogocentrismo, en la medida en que reproduce la asignación de la transcendencia a lo masculino y la materialidad a lo

Madrid, Traficantes de Sueńos; y para un acercamiento al pensamiento feminista descolonial desarrollado en México, Millán Márgara (coord.), Más allá del feminismo: caminos para andar, México, Red de Feminismos Descoloniales, 2014.

12 El término queer hace referencia a un movimiento político crítico con la normalización de la homosexualidad, nacido en EE.UU. en la periferia del movimiento gay. Lo queer, en inglés, torcido, extraño, marica o rarito es un insulto del que las minorías sexuales se apropian con el objetivo de criticar la asimilación, rescatando la experiencia de determinados sujetos situados en los márgenes, al tiempo que se plantea la imposibilidad de codificar la identidad de manera definitiva debido a su multiplicidad. En torno a lo queer existe una enorme producción académica, artística y cultural que se centra en los problemas de la identidad y de la diferencia. La primera en utilizar el término "Teoría Queer» fue Teresa de Lauretis; posteriormente, la publicación de $E l$ género en disputa de Judith Butler hizo saltar el debate a nivel internacional. Estos estudios han dado pie a una interesante discusión en el interior del feminismo en torno a la identidad del sujeto del feminismo en la que se cuestiona lo femenino como esencia.

13 Spivak, Gayatri Chakravorty, ¿Puede hablar el subalterno?, Buenos Aires, El Cuenco de Plata, 2011. 
femenino. En su lectura de Luce Irigaray, la diferencia femenina aparece como una potencia que permite desestabilizar dicha separación. Una potencia que muestra cómo el sujeto no es producto de decisiones racionales, sino el resultado complejo de la interacción de fuerzas sociales y simbólicas que se inscriben en el cuerpo. ${ }^{14}$ Aquí se abre un paréntesis en la identificación del sujeto con la conciencia, un paréntesis desde el que formular nuevas preguntas. Si el sujeto se descubre arrojado a un mundo que no controla -esas fuerzas intempestivas que todo lo inundan-, ¿quiero esto decir que se anulan la ética, la responsabilidad y el compromiso con el mundo? Si estoy determinado por algo que me precede, ¿solo puedo someterme a lo que se cierne sobre mí? ¿No puedo más que plegarme a la pérdida de control? Judith Butler lo plantea del siguiente modo:

Mi relato de mí misma es parcial y está acosado por aquello para lo cual no puedo tener una historia definitiva. No puedo explicar con exactitud por qué he surgido de esa manera, y mis esfuerzos de reconstrucción narrativa siempre están sometidos a una recesión. Hay en mí, y me pertenece, algo acerca de lo cual no puedo dar cuenta. Pero, ¿significa esto que no soy en el sentido moral, responsable de lo que soy y lo que hago? ${ }^{15}$

Los feminismos enseñan al respecto que cabe un hacer comprometido no heroico que, en lugar de negar su responsabilidad, se compromete con la parcialidad y la precariedad. Dicho de otro modo: a sabiendas de que toda práctica es limitada, contradictoria y compleja, no se cede a la inacción; por el contrario, al individuo solo le queda implicarse en el mundo desde la convicción de ser uno más y, por tanto, de estar enraizado junto a otros en él. ${ }^{16}$ Desde esta perspectiva, la experiencia del cuerpo es clave para reconstruir el compromiso. Por una parte, nos vincula de manera primaria con el mundo, recordando que requerimos recursos, afectos y cuidados externos. Por otra, dicha experiencia suspende las pretensiones de conocer independientemente de las marcas corporales que organizan la existencia. Sin embargo, del mismo modo que sucede con la ética, esta exigencia de anclaje al cuerpo no conlleva necesariamente una renuncia a un conocimiento válido. Siguiendo a Donna Haraway, no se trata ni de abandonar el acceso a lo general ni de ceder al relativismo, sino de denunciar cómo la aparente neutralidad de lo objetivo oculta privilegios y desigualdades. Dicho de otro modo: está en

\footnotetext{
${ }_{14}$ Braidotti, Rosi (2002), Metamorfosis. Hacia una teoría materialista del devenir, Madrid, Akal, 2005, p. 37.

15 Butler, Judith (2005), Dar cuenta de si mismo. Violencia ética y responsabilidad, Buenos Aires, Amorrurtu, 2009, p. 60.

${ }_{16}$ Para profundizar en este aspecto, Judith Butler explica de mano de Foucault los motivos de una ética que no cuenta con los preceptos idealistas, pero que sin embargo es necesaria para la creación de sí. Butler, Judith, "¿Qué es la crítica? Un ensayo sobre la virtud de Foucault», 2002, en VV.AA., Producción cultural y prácticas instituyentes. Lineas de ruptura en la crítica institucional, Madrid, Traficantes de sueños, 2008.
} 
juego producir otro tipo de verdades, siempre situadas, en una suerte de versión feminista de la objetividad; versión que «trata de la localización limitada y del conocimiento situado, no de la transcendencia y el desdoblamiento del sujeto y el objeto. Caso de lograrlo, podremos responder de lo que aprendemos y de cómo miramos». ${ }^{17}$

En último lugar, el tiempo entendido como presencia va a ser cuestionado desde diferentes ángulos. Si atendemos a figuras históricas poco visibles como hilanderas, programadoras o cuidadoras, se percibe otra temporalidad en la que la trama de hilos, afectos y conversaciones solo puede comprenderse en términos de proceso, tránsito y simultaneidad: aquello que, como dice Deleuze, tiene la forma del verbo infinitivo, siempre en movimiento, siempre en un presente que se nos escapa, porque es lo que ocurre entre un punto y otro o al mismo tiempo en varios puntos. Pero devenir que no es meramente repetición porque involucra un cambio hacia otra cosa no predeterminada -la tela que compondrá una prenda aún por hacer, la conversación que lleva a otra aún por decir-. Esta temporalidad se rige por una lógica distinta: hecha de ausencias necesarias -como el silencio en el conversar o las retaguardias en la política-; intensidades variables, no siempre álgidas; y también abierta a imprevistos: escapa al tiempo estratégico medido por el cálculo de la razón. Los efectos para pensar la política son importantes: se resquebraja la dicotomía entre acción visible y pasividad invisible; entre presencia inmediata y ausencia permanente; entre adentro y afuera (¿qué mapa resulta cuando pensamos la simultaneidad de los acontecimientos? ¿Qué tantas cosas suceden para que un sentido pueda ser producido por una comunidad?) y permite, por último, pensar otros modos de implicación y compromiso. ${ }^{18} \mathrm{Al}$ fin al cabo, como insiste Braditotti, el inconsciente nos abre a una temporalidad distinta, donde ni la voluntad ni la razón pueden predecir el curso de la transformarse de las cosas.

\section{Universales concretos y cuerpos diversos}

Si ESTIRAMOS EL TRAZO DE ESTA ONTOLOGÍA, que desplaza la metafísica de la presencia con sus diferentes vórtices unidad, totalidad, razón y presencia, hacia el problema de la acción política, aparece una de las grandes preguntas de nuestro tiempo: cómo no renunciar a la política cuando ya no contamos con un sujeto Uno. Un

\footnotetext{
17 Haraway, Donna (1991), Ciencia, cyborgy mujeres, la reinvención de la naturaleza, Madrid, Cátedra, 1995, p. 327.

${ }^{18}$ Una importante reflexión sobre el compromiso se encuentra en el libro de Marina Garcés, Un mundo común, Barcelona, Bellaterra, 2013.
} 
sujeto, además, que describimos no desde la transparencia, sino desde la complejidad de los nudos que lo desbordan y lo hacen incomprensible también para sí.

Una de las aristas de este problema tiene que ver con la crítica a los universales: cómo hacer para que la afirmación de una posición arraigada en la particularidad no suponga ceder al relativismo. ¿Puede lo particular llegar a expresar lo general? Por un lado, si se comprende lo particular como riqueza y no como carencia, se introducen puntos de vista que expanden el sentido de la realidad, en la medida en que lo universal es redefinido por las diferentes particularidades. Por otro, las particularidades pueden contener en sí algo más que ellas mismas, negando su propio estatus de oposición al universal: ser expresión de un tiempo histórico determinado, de un problema que es de muchos o de una situación estructuralmente injusta como la de los sin papeles en Europa o la desaparición de los 43 estudiantes normalistas de Ayotzinapa, desaparecidos en México, que simbolizan la situación general de un país-. En estos casos, lo particular deja de ser aquello que no puede salir de sí y deviene un tipo de universal no sumido en la abstracción: el universal concreto (en el sentido hegeliano: el concepto con todas sus determinaciones que no es mera abstracción ni tampoco mera particularidad).

Por otro lado, ante la crítica a las totalizaciones, la pensadora latinoamericana Raquel Gutiérrez señala la necesidad de establecer un "nosotras» concreto, pero también expansivo, es decir, que tenga capacidad de generalización. ${ }^{19}$ Este tipo de «nosotras» presupone un concepto no sustantivo, abierto y contingente de comunidad, que no permanece cerrado sobre sí, sino que se abre hacia lo que no es. Por tanto, no ceder a las posiciones relativistas nos sitúa ante un desafío doble: pensar lo general desde los universales concretos y aspirar a ir más allá de las diferencias desde la redefinición expansiva del nosotros. ${ }^{20}$

La siguiente arista tiene que ver con las implicaciones de un punto de vista materialista. Mucho se habla del cuerpo en los debates contemporáneos, pero, ¿cómo es significado en los ordenamientos sociales y en las resistencias? El cuerpo es la primera instancia de relación social, límite y abertura de lo que somos. Pese a su importancia, existe una tendencia a obviarlo, a desprendernos: ¡cómo escapar al proceder abstracto de la razón que interpreta sin tocar la vida, sin considerar las marcas que el poder produce, las fuerzas irracionales, las memorias colectivas inscritas en ellos? ¿Cómo mostrar que las relaciones de dominio no están hechas solo

\footnotetext{
19 Gutiérrez, Raquel, «Políticas en femenino: transformaciones y subversiones no centradas en el Estado. Tensiones entre las heterogéneas lógicas de producción de lo común y los Estados plurinacionales», en Escárzaga, Fabiola; Gutiérrez, Raquel; Carrillo, Juan José; Capece, Eva; Nehe, Börries (coords.), Movimiento indígena en América Latina: resistencia y transformación social. Vol. III, UAM-X, BUAP y CIESIAS, México, 2014, p. 93.

${ }^{20}$ En este sentido, cabe hablar de una política de lo común que trata no solo de forjar alianzas entre singularidades, sino de desplegar aquello común que sostiene toda realidad.
} 
de entelequias, sino que modulan cuerpos, reproduciendo posiciones de dominio diversificadas, haciendo este cuerpo -racializado, generizado- para tal lugar? De manera muy similar a la que encontramos en la historia de los feminismos, los procesos de politización de los últimos tiempos ${ }^{21}$ parecen intuir en algún sentido estos problemas, expresando, de diversas maneras, una politica de la intersubjetividad en la que el primer desafío es reconstruir los vínculos y recuperar la posibilidad de decir «nosotros» que parecía desterrada. La materia de esa política son los cuerpos: sin etiquetas, sin banderas, sin programas predefinidos. ${ }^{22}$ Desde este punto de partida, es más fácil hablar de los malestares presentes en la sociedad, bajar el discurso al nivel de las ambivalencias y dificultades de la realidad cotidiana, así como percibir de modo más cercano o realista la posibilidad de cambiar las cosas -se pasa de la idea de revolución totalizante entendida como "asalto al Palacio de Invierno» a pequeñas victorias que ensanchan el universo de lo posible-- ${ }^{23}$

\section{Desafíos políticos en tiempos de crisisł política de lo común}

Uno de los problemas CRUCiales de nUestro tiempo es la crisis de la idea de revolución tal como ha sido desplegada históricamente. A partir de esta crisis, necesitamos preguntar: ¿¿de qué están hechas las batallas en la actualidad? Cuando la realidad ha sido despojada de la acción política, no basta con afirmar una posición ideológica predeterminada: es necesario dar un paso atrás para reconstruir el mismo campo en el que tiene lugar la pelea, tejer el escenario en el que se produce, así como desarrollar complicidades con quiénes podrían estar implicados en ella. En este sentido, el desafío más importante en la actualidad es volver a decir "nosotros». Necesitamos, se necesita, reconstruir la vida en común.

Por tanto, puede decirse que el primer desafío en esta dirección es una precondición de los demás: reta a no renunciar a la política en un contexto de crisis de las antiguas formas de organización y de los relatos clásicos de emancipación social. Ante la diversidad de realidades y sujetos, la política debe hacer no de la unidad, sino de lo común su materia prima, situándose en la difícil tesitura de construir articula-

\footnotetext{
${ }^{21}$ A los que nos referimos más arriba: el 15m en España, Occupy en USA, \#YoSoy132 y \#TodosSomosAyotzinapa en México, los estudiantes indignados en Chile, el movimiento Passe Livre de Brasil, etc.

${ }^{22}$ Para un análisis de la naturaleza de estos movimientos y sus vínculos con los feminismos véase el trabajo de Rovira, Guiomar «De las redes activistas a las multitudes conectadas. Movilización social, protesta global y tecnologías de la comunicación», en Pensamiento Político, I Época, Vol. 10, 2015, pp. 157-170. doi: http:// pensamientopolitico.org/Descargas/RIPP10157170.pdf

23 Por este motivo, demandas realizadas en el marco de estas politizaciones se han considerado reformistas, obviando que propuestas de ruptura total, aunque sean deseables, no son percibidas como horizontes reales, y por tanto, desmovilizan.
} 
ciones entre diferentes, abrir procesos amplios desde los que nombrar la experiencia contemporánea e imaginar la vida con otros criterios ético-políticos. ${ }^{24}$ En la actualidad, existen experiencias que exploran en esta dirección. Las mareas ciudadanas en contra de los recortes en el Sur de Europa o las luchas contra el despojo de agua o tierra en lugares de Latinoamérica hacen de lo que es de todas las personas, de lo que es común, una prioridad. En este «todas» caben muchas realidades, que son conectadas por preocupaciones o ideas compartidas. Por ejemplo, quienes defienden la sanidad pública en España dicen "queremos cuidaros a todas las personas», no luchan solo por lo suyo, sino que la privatización de la salud se vincula con la capacidad o incapacidad que tiene una sociedad para proporcionar una vida saludable a todas las personas. Hay que pensar el potencial aglutinador, antirracista y anticlasista de esta afirmación. Desde estas experiencias, vemos cómo sin contar con un sujeto político predefinido o un programa calculado, es posible ir más allá de la mera afirmación de luchas particulares. Aquí, emergen las políticas de lo común.

El segundo desafío tiene que ver con el debate acerca de cómo queremos vivir. En algunas partes del planeta, se lucha por dignificar la vida, recuperar derechos perdidos; en otras, simplemente por sobrevivir en medio de economías de muerte. Pero en todos los casos el modelo vigente que sitúa la búsqueda de beneficio por encima de la vida parece ser fuente de un malestar creciente e incluso insostenible. La famosa sentencia de Frederic Jameson de que es más fácil imaginar el final del mundo que el final del capitalismo parece tambalearse: se ha abierto un agujero en el relato neoliberal que cuestiona su sentido, lo interroga y apremia con demandas de justicia o democracia real. ${ }^{25}$ Sin embargo, además de saber cómo no queremos vivir, es necesario empezar a preguntar: ¿cómo sería una vida que merezca la pena ser vivida? ¿Qué aspectos de la actual organización socioeconómica habrían de ser modificados? Esta pregunta no puede quedar encajonada en una única esfera, sino que debe expandirse hasta sacudir la sexualidad, el cuerpo, la educación y la salud, desbordando las divisiones público/privado-producción/reproducción. Hay que preguntar también: ¿Cómo serían un cuerpo o una sexualidad vivibles? ¿Qué es exactamente lo que defendemos cuando exigimos una buena vida o una digna de ser vivida: una basada en la hegemonía del ideal de independencia ${ }^{26}$ en la que cada

${ }^{24}$ Para ello, es necesario, por una parte, una política de la escucha, de la atención y del aprendizaje que permita descubrir lo que hay de común en la experiencia cotidiana. Aquellos lazos, más o menos elaborados que compartimos, querámoslo o no, con otros por el hecho de existir. Por otra, una política imaginativa que no se quede en lo que hay, sino que genere otros sentidos en el interior de las relaciones sociales.

25 Así lo expresan las revueltas populares que tienen lugar en el mundo entero desde 2011.

${ }^{26}$ La subjetividad neoliberal se produce construyendo un ideal de independencia que afirma tres cosas: a) la conciencia se basta a sí misma para ser y conocerse; b) la vida es un proyecto individual que nada tiene que ver con la experiencia colectiva; y c) somos física y emocionalmente autosuficientes: no necesitamos que nadie nos cuide. 
individuo es libre de competir en el mercado o una para la que cuente cada vida con criterios de igualdad y que, por tanto, debe ser cuidada? ¿Qué significaría desde esta óptica cuidar la vida: a qué tipo de relación con el universo humano y no humano nos convoca? En otras palabras, ¿cuáles son los diferentes sentidos encerrados en el concepto "vida», cuáles queremos desplegar y por los que merece la pena batallar colectivamente?

Hacer estas preguntas desde la perspectiva del cuidado, desde la perspectiva de los procesos que sostienen cotidianamente la vida, contribuye a reconocer los límites de la subjetividad individualista neoliberal. El cuidado, debido a que implica en sí relación, recuerda que la vida no es posible sin el vínculo con los otros. Pero no solo en lo que concierne a la dependencia física y emocional entre individuos: también en un sentido ontológico -cuyo fundamento se apoya en la deconstrucción de la metafísica propuesta-, en el que descubrimos que la propia conciencia solo puede conocerse a sí misma a través del Otro -el lenguaje, las normas, la mirada-. Frente a un poder que separa la vida, produciendo individuos aislados en competencia entre sí, redescubrir el vínculo -discontinuo, no pleno- que me une al mundo es la gran batalla que se abre. Aquí, el cuidado tiene la capacidad de mostrar la vulnerabilidad de los cuerpos y, con ella, la naturaleza inacabada del ser. En este sentido, contribuye a cuestionar el sueño de autosuficiencia y plenitud occidental, recuperando los contornos de una realidad de cuerpos conectados desde su singularidad, en común.

Pero, ¿cómo pensar la comunidad para no reproducir una idea estática o una identidad cerrada en la que se naturalicen determinadas relaciones sociales o la lógica de una nueva sustancia, pero más grande? En esta discusión, es preciso distinguir dos planos. Uno, que tiene que ver con los contenidos y con los aspectos organizativos de una comunidad. Otro, que analiza sus presupuestos filosóficos, es decir, interroga la misma noción de "comunidad», y lo hace a partir de los aprendizajes feministas.

En el primer plano, aparecen tres retos imbricados entre sí que, sin embargo, tienen aristas diferentes. El primero: ante la privatización y el despojo, defender bienes comunes materiales como agua, tierra, bosques y energía, que son condición de existencia para poblaciones enteras ${ }^{27}$ por otro lado, permitir la libre circulación de bienes inmateriales como conocimiento, cultura, información e Internet, indispensables para profundizar en las aspiraciones democráticas; $y$, por último, organizar la

\footnotetext{
27 Sobre las luchas actuales contra el despojo de los bienes comunes puede verse, a modo de ejemplo paradigmático, el volumen que recoge algunas luchas clave contra el despojo en Latinoamérica: Composto, Claudia y Navarro, Mina Lorena (comp.), Territorios en disputa. Despojo capitalista, luchas en defensa de los bienes comunes naturales y alternativas emancipatorias para América Latina, México, Bajo Tierra Ediciones, 2014.
} 
sociedad en función del bien colectivo, y no de intereses privados (como cuando se insiste en la necesidad de instituciones al servicio de la gente).

Pero si atendemos el abordaje filosófico, vemos que no basta con gestionar o administrar aquello considerado común: es preciso examinar los fundamentos que sostienen el sentido que le damos a la comunidad, en tanto que el sentido implícito condiciona el modo en el que se emprende la tarea de construirla. Por una parte, puede interpretarse como una suma de identidades pre-existentes; identidades que accederían a la comunidad para compartir algo que tienen previamente (una idea, una religión, una forma de vida, un territorio). Esta interpretación asume que existe un momento previo en el que el sujeto es independiente de la relación; momento en el que se constituye para posteriormente poner en común aquello que le pertenece. Sin embargo, como sostiene Raquel Gutiérrez, aquí lo común sigue considerándose como una sustancia: se piensa desde el tener. Para desligarlo de la propiedad, es necesario abordarlo no como aquello con una realidad plena dada previamente que se comparte, sino "como algo que se produce, reproduce y reactualiza continua y constantemente». ${ }^{28}$ Esta noción productiva en la que lo compartido debe ser inventado, nos acerca a la idea del ser en relación -en la que no se basta a sí mismo para ser, en la que el principio es la incompletud-: la identidad se forma en su exposición permanente con el Otro, nunca de manera definitiva, de modo que lo común no puede clausurarse en una forma restringida de sociedad. En este sentido, lo común está atravesado por la diferencia radical; es decir, no solo difiere de algo externo (aquello que no forma parte de la comunidad), sino que también difiere de sí (siempre está rota por dentro). Este diferir de sí sucede a su vez de dos modos: en la relación abierta con lo que no se es -con aquello que está más allá de cada cual, con aquello que se nos escapa: no hay soberanía posible en la comunidad, decía Maurice Blanchot-; y, por otro lado, en el de un sentido que no está dado de antemano en la misma comunidad, sino que debe ser producido. Por tanto, esta afirmación de la diferencia impide deducir de manera automática el significado de una comunidad (no hay posibilidad de retornar a un pasado en el que la comunidad supuestamente sí era plena). Aún más: en la medida en que lo común no es sustancia, sino relación, es imposible afirmar de manera definitiva «me pertenece». Esta negatividad constitutiva, es antídoto contra el esencialismo comunitarista.

Pero, precisamente, asumir la dificultad de habitar el espacio común y la subjetividad de manera plena, abre una pregunta final: ¿cómo es posible entonces seguir

\footnotetext{
${ }^{28}$ GutiérRez, RaQuel, «Políticas en femenino: transformaciones y subversiones no centradas en el Estado. Tensiones entre las heterogéneas lógicas de producción de lo común y los Estados plurinacionales», en Escárzaga, Fabiola; Gutiérrez, Raquel; Carrillo, Juan José; Capece, Eva; Nehe, Börries (coords.), Movimiento indigena en América Latina: resistencia y transformación social. Vol. III, México, UAM-X, BUAP y CIESIAS, 2014, pp. 281.
} 
diciendo «nosotros»? ¿Cómo mantener el compromiso con lo común cuando la diferencia radical lo declara en cierto modo imposible? Este es el asunto: ¿Y no ofrecen las aportaciones feministas señaladas pistas para ello: una política no de la totalidad, sino de lo inacabado? ¿Una política que no renuncia a afirmar, sino que lo hace de otro modo desmontando los mismos cimientos del pensar? 


\section{Referencias Bibliográficas}

Butler, Judith, Dar cuenta de sí mismo. Violencia ética y responsabilidad, Buenos Aires, Amorrurtu, 2009.

— "¿Qué es la crítica? Un ensayo sobre la virtud de Foucault», 2002, en VV.AA., Producción cultural y prácticas instituyentes. Lineas de ruptura en la critica institucional, Madrid, Traficantes de sueños, 2008.

Butler, Judtih; Laclau, Ernesto y Zizek, Salvoj, Contingencia, hegemonia y universalidad. Diálogos contemporáneos de la izquierda, México: Fondo de Cultura Económica, 2003.

Braidotti, Rosi (2002), Metamorfosis. Hacia una teoría materialista del devenir, Madrid, Akal, 2005.

Composto, Claudia y Navarro, Mina lorena (comp.), Territorios en disputa. Despojo capitalista, luchas en defensa de los bienes comunes naturales y altenrativas emancipatorias para América Latina, México, Bajo Tierra Ediciones, 2014.

Garcés, Marina, Un mundo común, Barcelona, Bellaterra, 2013.

Gutiérrez, Raquel, "Políticas en femenino. Reflexiones acerca de lo femenino moderno y del significado de sus políticas», en Millán, Márgara (coord.), Más allá del feminismo: caminos para andar, México, Red de Feminismos Descoloniales:, 2014, pp. 87-98.

— «Políticas en femenino: transformaciones y subversiones no centradas en el Estado. Tensiones entre las heterogéneas lógicas de producción de lo común y los Estados plurinacionales», en Escárzaga, Fabiola; Gutiérrez, Raquel; Carrillo, Juan José; Capece, Eva; Nehe, Börries (coords.), Movimiento indígena en América Latina: resistencia y transformación social. Vol. III, México, UAM-X, BUAP y CIESIAS, 2014, pp. 275-299.

Gil, Silvia L., Nuevos Feminismos. Sentidos comunes en la dispersión, Madrid, Traficantes de Sueños, 2011.

Rovira, Guiomar «De las redes activistas a las multitudes conectadas. Movilización social, protesta global y tecnologías de la comunicación», en Pensamiento Político I Época, Vol. 10, 2015, pp. 157-170.

Haraway, Donna (1991), Ciencia, cyborg y mujeres, la reinvención de la naturaleza, Madrid, Cátedra, 1995.

Irigaray, Luce (1974), Espéculo de la otra mujer, Madrid, Akal, 2007. 
Lacan, Jacques (1975), Aun. Seminario 20, Buenos Aires, Paidós, 2008.

Lauretis, Teresa De, Diferencias. Etapas de un camino a través del feminismo, Madrid, Horas y horas, 2000.

Lorde, Audre, Zami: A new spelling of my name; NY, The Crossing Press, 1982

Millán, Márgara (coord.), Más allá del feminismo: caminos para andar, México, Red Feminismos Descoloniales, 2014.

Pateman, Carol, «El estado de bienestar patriarcal», en Contextos, Año 2 No 5., Lima, Programa de Estudios de Género Pontificia Universidad Católica del Perú, 2000.

Spivak, Gayatri Chakravorty, ¿Puede hablar el subalterno?, Buenos Aires, El Cuenco de Plata, 2011.

Zupančič, Alenka; Copjec, Joan y Cevasco, Rithée, Ser-para-el-sexo. Diálogo entre filosofia y psicoanálisis, Barcelona, Ediciones del Centro de Investigación Psicoanálisis y Sociedad, 2013.

VV.AA., Estudios Postcoloniales. Ensayos fundamentales, Madrid, Traficantes de Sueños., 2008.

DOI: http://dx.doi.org/10.15366/bp2018.18.011

Bajo Palabra. II Época. No18. Pgs: 237-254 